Western North American Naturalist 67(4), (C) 2007, pp. 538-548

\title{
CENSUSING BOBCATS USING REMOTE CAMERAS
}

\author{
Eveline S. Larrucea ${ }^{1}$, Gianluca Serra ${ }^{2}$, Michael M. Jaeger ${ }^{2,3}$, and Reginald H. Barrett ${ }^{2}$
}

\begin{abstract}
We estimated bobcat (Lynx rufus) density for 3 different locations in northern California using active infrared-triggered cameras. Using differences in pelage pattern as well as other physical characteristics, we identified individual bobcats from photographs, and used mark-recapture techniques to estimate population density. Camera density affected the precision of population estimates. The same population was estimated using camera densities of $0.5,1,2,4$, 6 , and 8 cameras $\cdot \mathrm{km}^{-2}$. Higher camera densities resulted in more captures and recaptures of bobcats and, consequently, in more precise density estimates. Similarly, the number of photo-captures and recaptures increased with increasing study duration. Increasing the area sampled resulted in the capture of more individuals but did not increase the percentage of recaptures. While some locations captured multiple bobcat photographs (e.g., 15 at 1 station), these photos tended to be recaptures of the same individual. There were no more than 2 individuals photo-captured at any 1 camera location. Bobcat density varied among habitat types as predicted. We estimated density as 0.27 bobcats $\cdot \mathrm{km}^{-2}(s=$ $0.16)$ overall in an area in the northern Sacramento River Valley and as 0.35 bobcats $\cdot \mathrm{km}^{-2}(s=0.56)$ in a steep and rocky canyon within the area. At a 3rd site in the Coast Range, the estimate was 0.39 bobcats $\cdot \mathrm{km}^{-2}(s=1.44)$. Bobcats were more diurnal where human activity was less common. In addition, photo-capture was significantly higher along roads and trails without an attractant than it was off-trail with an attractant.
\end{abstract}

Key words: bobcat, California, census, infrared-triggered camera, Lynx rufus, Red Bluff, Sacramento Valley.

Bobcats (Lynx rufus) are reported to be nocturnal, secretive mammals that prefer steep, rocky habitat with vegetation cover (Litvaitis et al. 1986). Individual bobcats can roam large areas, and the size of their home range depends on the habitat quality and prey density. These behaviors make it difficult to obtain accurate density estimates. Indices of relative abundance have been used as an alternative measure; these indices include the number of trap-nights per individual captured (e.g., Wood and Odum 1964, Jenkins et al. 1979), numbers harvested (e.g., O'Brian and Boudreau 1998), snow tracking (e.g., Golden 1995), mail questionnaires sent to landowners (Anderson 1987), or scent-station surveys (e.g., Linhart and Knowlton 1975, Johnson and Pelton 1981, Conner et al. 1983). These methods have been shown to have biases between the sexes, age classes, and social statuses of animals recorded (Diefenbach et al. 1994).

Mark-resight methods have been shown to be a reliable way to census populations. However, these methods are rarely used for carnivores because marking them can be very labor intensive due to the difficulty of capturing the animal (e.g. Neale 1996). Resighting also can be difficult for species that are secretive, nocturnal or far-ranging, and for species that occur at low densities. Hibi and Jeffery (1987) were the first to suggest using photo-capture of animals with individually distinct pelage markings as a way to mark-resight without the need for capture. Mace et al. (1994) reported the 1st successful use of a photographic mark-recapture approach, combined with radiotelemetry, to estimate the size of a grizzly bear (Ursus arctos) population in Yellowstone National Park. This approach has subsequently been used with tigers (Panthera tigris; Karanth 1995, Karanth and Nichols 1998, Kawanishi and Sunquist 2004), jaguars (Wallace et al. 2003, Silver et al. 2004, Soisalo and Cavalcanti 2006) and marked white-tailed deer (Odocoileus virginianus; Jacobson et al. 1997). Bobcats also have unique markings that can be used to distinguish individuals by photo-capture (Heilbrun et al. 2003).

The numbers and placement of camera stations have varied widely among studies. For example, Karanth and Nichols (1998) spaced cameras $2-3 \mathrm{~km}$ apart along road transects.

\footnotetext{
${ }^{1}$ Department of Biology, Program in Ecology, Evolution and Conservation Biology, University of Nevada, Reno, NV 89557. E-mail: esequin@unr.nevada.edu

${ }^{2}$ Department of Environmental Science, Policy and Management, University of California-Berkeley, Berkeley, CA 94720.

${ }^{3}$ Present address: USDA APHIS WS National Wildlife Research Center, Department of Wildland Resources, Utah State University, Logan, UT 84322.
} 
Soisalo and Cavalcanti (2006) placed 2-3 cameras within the home ranges of female jaguars at sites where radiotelemetry locations were clustered. Kawanishi and Sunquist (2004) used 1 camera $\cdot 4 \mathrm{~km}^{-2}$ on three $200-\mathrm{km}^{2}$ sites where roads generally did not occur. The study on white-tailed deer used camera densities of 0.4, 0.8 , and 1.5 cameras $\cdot \mathrm{km}^{-2}$ (Jacobson et al. 1997) in a $40.5-\mathrm{km}^{2}$ area. At the highest camera density they were able to photograph $100 \%$ and $82 \%$ of collared deer in 2 sessions. In other studies, the number of available cameras is limited and their placement is determined by size of the area of interest, availability of roads, and location of tracks or scats.

In this study we used remote infrared-triggered cameras to estimate the density of bobcats in 3 different habitats at 2 locations in northern California. We examined the effect of different camera densities and areas sampled on these estimates. In addition, we investigated whether most photo-captures tended to be collected from only a few well-placed cameras.

\section{Methods}

\section{Study Area}

The study was conducted on the $130-\mathrm{km}^{2}$ Grey Davis Dye Creek Preserve (DCP) of the Nature Conservancy near Red Bluff, California. The preserve lies at the edge of the northern Sacramento Valley in the foothills of the Cascade Range at elevations ranging from 50 to $700 \mathrm{~m}$. Lower elevations are predominantly annual grasslands, while hills and ridges are covered in blue oak (Quercus douglasii) woodland. Several drainages and canyons support dense riparian vegetation. The climate is dry and hot during summer and wet and mild during winter. Although the preserve was closed to the public, both a cattle operation and a guided hunting operation for pigs (Sus scrofa), deer (Odocoileus hemionus), and game birds were run on the preserve. Most human activity took place in the relatively small area surrounding the headquarters area. The backcountry section (DCP-B) was irregularly traveled by hunters and cowboys and was generally much more secluded.

The 2nd study area was at the Hopland Research and Extension Center (HREC) in California's Coast Range. The 21.4- $\mathrm{km}^{2}$ University of California sheep research facility ranges in elevation from 200 to $900 \mathrm{~m}$. The cli- mate is dry and hot during summer and wet and mild during winter. The vegetation is a mosaic of 4 habitat types: grassland $(27 \%)$, woodland-grass (33\%), dense woodland (20\%), and chaparral (19\%; Murphy and Heady 1983). Much of the study area is steep with rocky, densely vegetated seasonal drainages. Human use away from the headquarters area was primarily by shepherds and researchers capturing and radio-tracking bobcats and coyotes (Neale and Sacks 2001). The majority of this activity occurred during daylight hours.

\section{Camera Setup}

We used infrared-triggered, commercially made TrailMaster ${ }^{\circledR}$ TM-1500 active camera trap units (Goodson and Associates, Inc., Lenexa, KS). Each unit consisted of a 35-mm weather resistant camera, an infrared transmitter, and a receiver (Kucera and Barrett 1993). The camera was triggered when the infrared beam was interrupted, and the receiver noted the date, time, and number of interruptions. We used 400 ASA print film with 24 exposures in 2 types of cameras, Yashica AW-Mini (Yashica Corp., Japan, modified by Goodson and Associates, Inc., Lenexa, KS) and Olympus Twin (Olympus Corp., Japan, modified by Goodson and Associates, Inc., Lenexa, KS).

Both the Yashika and Olympus camera types operated in the same manner, but in case there was a difference, the camera brands were alternated. Camera units were mounted on wooden frames held in place by rocks so that the infrared beam was at a height of $25 \mathrm{~cm}$. The infrared transmitter was placed 3-4 m from the receiver and the camera. All camera units were set to take pictures if the beam was blocked for at least 1 second (pulse delay of 2), and a camera delay of 2 minutes was set to avoid multiple photo-captures of the same individual on 1 visit. Bobcats tend to be solitary (Bailey 1974), so the chances that 2 adults walked by the camera station within the 2-minute camera delay time is unlikely. Clean cotton gloves were used during any handling of the cameras. Baits or lures were not placed at camera stations. The cameras were active 24 hours per day. Camera stations were visited once a week to check the condition of batteries, film, and general set-up. If needed, the cameras were realigned, and batteries and film were changed. Dates and times of photographs and incidents recorded by the receiver during the week were 

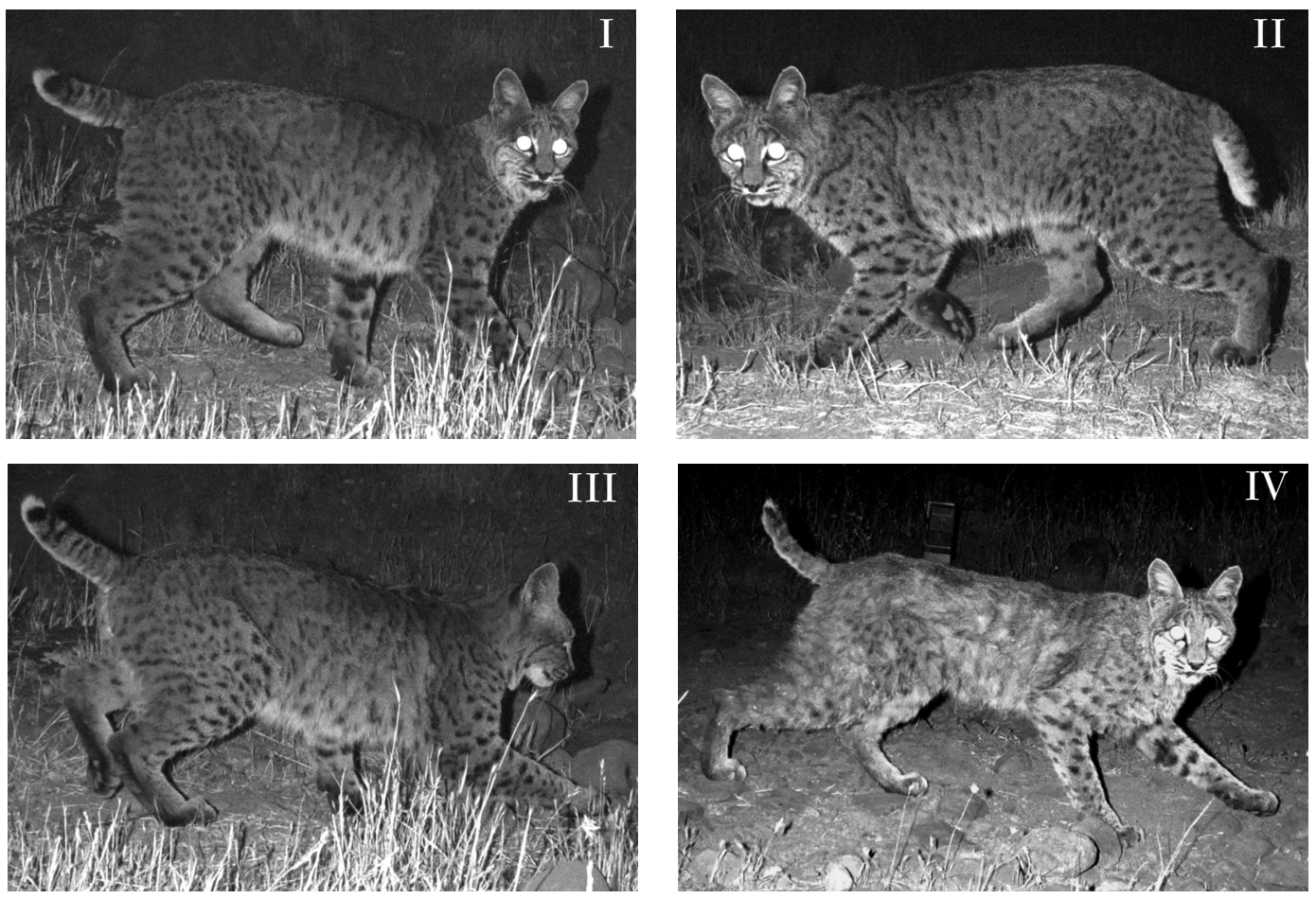

Fig. 1. Four images of the same bobcat identified by pelage markings. I-III comparison (refer to methods) used typical A-type matching of markings (markings on front shoulder and leg as well as rear knee are particularly distinctive). I-II comparison was completed in A-type fashion using facial markings (cheek pattern and above eyes) and scar on left ear. Image IV shows the same individual captured 2 years later (In addition to outer leg and facial markings I-IV comparison demonstrates inner left leg markings). Markings were still the same but the condition of the animal had changed.

recorded and cleared at this time. The detection efficiency of each trial was defined as the number of stations that photographed at least 1 bobcat divided by the total number of active stations.

\section{Individual Recognition}

All negatives with bobcats were scanned into a computer using a 35-mm negative scanner. This allowed us to increase the size of the image and also to compare multiple bobcats on the same screen. Hard copies of each image were printed for permanent records and further analysis.

Standardized criteria were used to assure objectivity in distinguishing individuals. Pelage patterns of bobcats are unique to each individual and are bilaterally asymmetrical (Koehler 1987, Heilbrun et al. 2003). A comparison was considered successful if a conclusion could be drawn about whether 2 photos showed the same individual $(+)$ or different individuals (-). Comparisons fell into 1 of 2 categories: both photos showed the same body side and/or the entire face (A-type), or the 2 photos showed opposite body sides and did not include the face (B-type; Fig. 1). An A-type comparison was based on the exact matching $(+)$ or mismatching (-) of conformation, design, and distribution of black pelage markings or scars on the same part of the body using procedures similar to Heilbrun et al. (2003).

We distinguished 2 levels of pelage pattern on an individual. On a fine scale, we used the shape, size, and exact location of single markings on the body, especially those on the face, tail, shoulders, and outer and inner legs (Fig. 1). On the broad scale, we used the relative density and size of markings as a composite, which is bilaterally symmetrical (Fig. 2). In addition, we used the presence and size of ear tufts, realizing that this may change seasonally for an individual. Dimensions and intensity of pelage colors were discarded as reliable features for individual recognition because they could not be standardized using this detection device. 

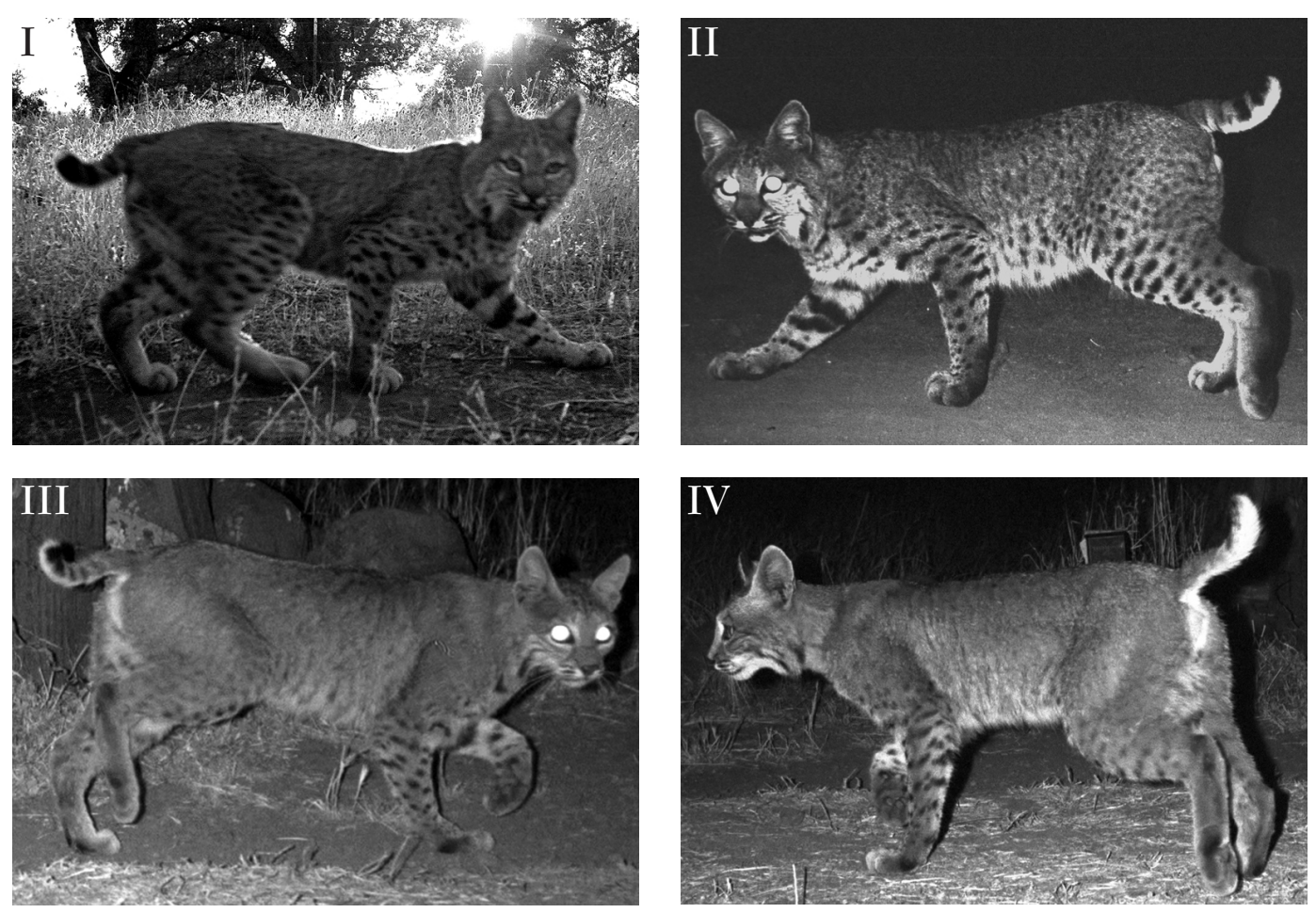

Fig. 2. Single markings were not bilaterally symmetrical, but overall size and distribution of pelage pattern were symmetrical. These left and right sides of 2 individuals (I+II and III+IV) demonstrate the symmetry of the degree of dappling of the coat. A B-type (B1) comparison of I-IV or II-III would have been (-). These photographs were all taken during the same season.

TABLE. 1 Camera sessions conducted over a $10-\mathrm{km}^{2}$ area at Dye Creek Preserve near Red Bluff, CA, 1998-2001. All cameras operated 24 hours per day.

\begin{tabular}{lccc}
\hline Trial & Date & Cameras $\cdot \mathrm{km}^{-2}$ & Trap-nights $^{\mathrm{a}}$ \\
\hline DC1 & Jan-Mar 1998 & 1.0 & 350 \\
DC2 $^{\mathrm{b}}$ & Sep-Dec 1999 & 6.0 & 2100 \\
DC $^{\mathrm{b}}$ & Sep-Dec 1999 & 2.0 & 700 \\
DC4 & May-Jun 2000 & 8.0 & 2800 \\
DC5 & Apr-May 2001 & 0.5 & 175 \\
DC6 & May-Jun 2001 & 4.0 & 1400 \\
\hline
\end{tabular}

${ }^{a}$ Number of active cameras times the number of nights each was in operation. bThese trials were run concurrently with half the study area covered by 2 cameras $\cdot \mathrm{km}^{-2}$ and half covered by 6 cameras $\cdot \mathrm{km}^{-2}$. After 5 weeks, camera densities were switched between sides.

B-type comparisons were based on the following: (1) general pattern of overall pelage markings, (2) presence and size of ear tufts, if resolvable, (3) overall conformation of the animal, and (4) photos being taken at the same or adjacent camera stations. All 4 had to agree for determination that photos were of the same animal. Photographs that were out of focus or taken from an oblique angle were discarded.
At a preliminary stage of photo-analysis, each photo was compared with all others. However, the number of cross-comparisons for a given survey decreases progressively as the number of resightings of the same individual increases. This is because if photo A shows the same bobcat as photo $\mathrm{B}$ and if photo $\mathrm{B}$ shows the same bobcat as photo $\mathrm{C}$, then the $\mathrm{A}-\mathrm{C}$ comparison is unnecessary. Eight coworkers examined all the photographs and determined the matches. The results from the matching trials were compared, and ambiguous photographs were removed from the mark-resight analysis.

\section{Camera Densities}

The effect of camera density on numbers of photo-captures and recaptures was tested at Dye Creek. Sampling was in a $10-\mathrm{km}^{2}$ area that was selected independently of knowledge of bobcat home ranges. Six densities were tested $(0.5,1.0,2.0,4.0,6.0$, and 8.0 camera stations per $\mathrm{km}^{2}$; Table 1). Camera locations were determined by placing grid squares of the appropriate 
size over a map of the study area. One camera was placed as close to the center of each grid square as possible, across either a dirt road or game trail. This protocol resulted in a relatively uniform coverage.

All camera stations were unbaited and active 24 hours per day. One additional camera markresight trial was conducted at HREC, and 2 were conducted in the backcountry of Dye Creek Preserve (DCP-B). At HREC the camera density was 0.5 cameras $\cdot \mathrm{km}^{-2}$ in a $24-\mathrm{km}^{2}$ area for 6 weeks. Due to high levels of human activity on the dirt roads, cameras were only activated from dusk until dawn (18:00-06:00). Camera stations were not baited. The 1st trial at DCP-B (trial DCP-B1) used 1 camera $\cdot \mathrm{km}^{-2}$ over a $24-\mathrm{km}^{2}$ area for 8 weeks. The 2 nd trial in DCP-B (trial DCP-B2) tested off-road (or off-trail) camera stations together with an attractant. Cameras were set at a density of 1 camera $\cdot \mathrm{km}^{-2}$. These camera sites were treated with Carman's Canine Call (Northwest Trappers Supply, Inc.), a lure advertised as effective on coyote, bobcat, and fox.

\section{Density Estimation}

After determining the number of bobcats from photo-matching, we constructed capture histories for each. The time and date stamped onto each photograph were cross-checked with data from receivers. Our sampling unit was defined as an individual adult bobcat at any particular camera station over a 24 -hour period. We divided each trial into five 1-week capture periods. If an individual bobcat was photocaptured 1 or more times during a l-week period, it was given a value of 1 . If the individual was not photo-captured during that week it was given a value of 0 . For example, an individual bobcat might have a capture history of 1-1-0-1-0 for the 5-week sampling period. These data were entered into the mark-recapture model in program CAPTURE in the X-matrix format (White et al. 1982). Although CAPTURE is able to estimate the density of a population, we used the program only to calculate abundances. Although our camera stations were relatively evenly spaced, they were not set up in a perfect grid, and therefore the data were not used for this estimation. We report results from CAPTURE as opposed to program MARK because similar studies on other species have been analyzed using CAPTURE, allowing for better comparison.
We calculated the area sampled as the area covered with camera traps plus a boundary strip (White et al. 1982). The boundary strip accounted for individuals from outside the trapped area that may have been photographed by peripheral cameras. This calculation represented the mean maximum distance moved (MMDM) by individual bobcats that were captured more than once (Wilson and Anderson 1985, Karanth and Nichols 1998). Half of this mean distance was used as the width of the boundary strip around the outermost traps. The boundary width was calculated separately for each camera trial. We used ArcView (ESRI, Redlands, CA) to calculate areas and perimeters. Density estimates were calculated by dividing the abundance estimates and their corresponding $95 \%$ confidence endpoints by the total area sampled. Adding a boundary strip increased the total area trapped, which in turn reduced density estimates. This provided a lowest potential estimate, which is appropriate for conservation efforts. For other applications it may be more desirable to use the true trapped area to determine a more direct estimate of individuals using the specific area.

\section{Results}

\section{Camera Density, Duration, and Coverage}

Higher camera densities resulted in more photo-captures of more individuals than did the lower camera densities (Table 2), and at the higher camera densities, proportionally more camera stations photographed bobcats (Fig. 3). While there were "hotspot" locations for photocaptures (e.g., 15 at 1 station) these tended to be recaptures of the same individual. There were no more than 2 individuals photo-captured at any 1 camera location (Fig. 4). Cameras with 5 or more photographs all photo-captured a bobcat within the first 2 weeks. In addition, higher densities resulted in more recaptures and greater precision in the estimate of bobcat abundance (Table 2). Standard error decreased with increasing numbers of recapture photographs $\left(\mathrm{R}^{2}=0.7118\right)$. A camera station was no more likely to capture a bobcat during the 2 nd half of the trial as compared to the 1st half $\left(\chi^{2}{ }_{1}=1.98, P=0.16\right)$.

Estimates of bobcat abundance and density for each of the 6 camera densities are included in Table 2 . The trend was for the bobcat density 
TABLE 2. Results from 6 trials at Dye Creek Preserve, 1998-2001.

\begin{tabular}{|c|c|c|c|c|c|c|c|c|c|c|}
\hline $\begin{array}{l}\text { Camera } \\
\text { densitya }\end{array}$ & Session & $\begin{array}{l}\text { No. of } \\
\text { photos }\end{array}$ & $\begin{array}{l}\text { Individuals } \\
\text { photocaptured }\end{array}$ & $\begin{array}{l}\text { No. of } \\
\text { recaptures }\end{array}$ & $\begin{array}{l}\text { Prob. of } \\
\text { capture }\end{array}$ & $\begin{array}{c}\text { Bobcat } \\
\text { estimate }\end{array}$ & $s_{\bar{x}}$ & $\begin{array}{l}95 \% \\
\text { C.I. }\end{array}$ & $\begin{array}{c}\text { Area } \\
\text { sampled } \\
\left(\mathrm{km}^{2}\right)\end{array}$ & $\begin{array}{l}\text { Density } \\
\text { (95\% C.I.) }\end{array}$ \\
\hline 0.5 & DC5 & 1 & 1 & 0 & - & - & - & - & 10.1 & - \\
\hline 1 & DCl & 10 & 3 & 7 & 0.333 & 3 & 0.856 & $3-5$ & 17.9 & $0.17(0.17-0.28)$ \\
\hline 2 & DC3 & 4 & 3 & 1 & 0.213 & 4 & 1.985 & $4-15$ & 18.4 & $0.22(0.22-0.81)$ \\
\hline 4 & DC6 & 18 & 4 & 14 & 0.450 & 4 & 0.520 & $4-5$ & 19.3 & $0.21(0.21-0.23)$ \\
\hline 6 & DC2 & 19 & 6 & 13 & 0.433 & 6 & 0.699 & $6-7$ & 21.9 & $0.27(0.27-0.34)$ \\
\hline 8 & DC4 & 44 & 6 & 38 & 0.667 & 6 & 0.161 & $6-6$ & 22.1 & $0.27(0.27-0.29)$ \\
\hline
\end{tabular}

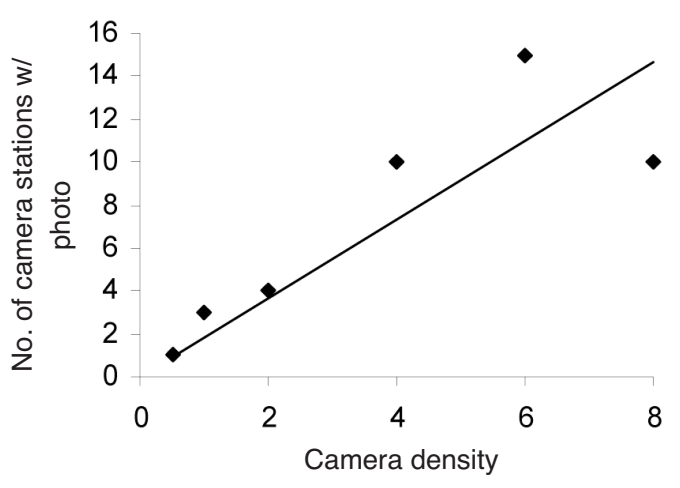

Fig. 3. The number of camera stations that captured at least 1 bobcat photograph increased with increasing camera density $\left(\right.$ cameras $\left.\cdot \mathrm{km}^{-2}\right)$.

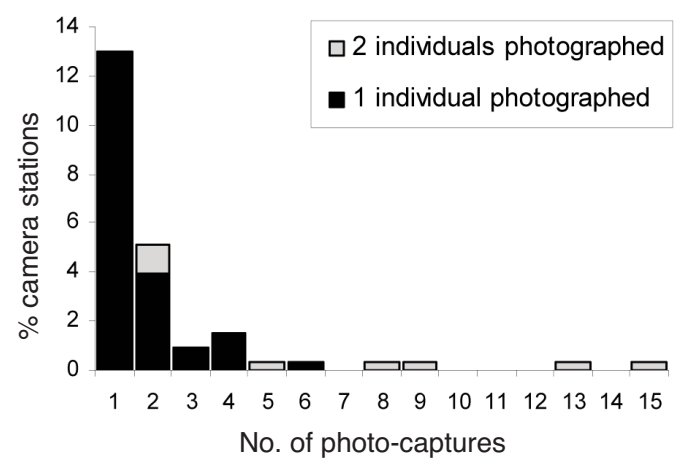

Fig. 4. Most camera stations with photo-captures obtained a single individual bobcat. Although some stations were hot spots for photo-captures, no stations obtained $>2$ individual bobcats.

estimate to increase with an increase in photocaptures and recaptures. The effective area sampled also tended to increase with increasing camera density (Table 2). The best estimate of bobcat numbers was 6 in an effective area of $22 \mathrm{~km}^{2}$ for a density 0.27 bobcats $\cdot \mathrm{km}^{-2}$. This estimate was the same for camera densities of 6 per $\mathrm{km}^{2}$ and 8 per $\mathrm{km}^{2}$. In addition, program CAPTURE calculated a number of betweenmodel test statistics that tested how well the data fit the assumptions of different models. The program found that the null model $\left(\mathrm{M}_{\mathrm{o}}\right)$ was the most appropriate one for both of our data sets. We ran data using $\mathrm{M}_{\mathrm{o}}$, but comparable results also were obtained using $\mathrm{M}_{\mathrm{h}}$. Similar results were obtained with program MARK.

The DCl trial $\left(1\right.$ camera $\left.\cdot \mathrm{km}^{-2}\right)$ was run for 9 weeks. Although we used only the first 5 weeks for the above comparison, the additional 4 weeks allowed us to determine whether the density estimate was improved by the longer time (Table 3). The effect of this was to increase the number of recaptures, which in turn lowered the standard error of the density estimate. The effect of the area sampled on the density estimate was determined comparing differently sized subsamples from trials DCl and DCP-B1. Larger areas increased the number of individuals photo-captured but did not increase the percentage of recaptures (Table 4). Density estimates tended to decrease with increasing sample area (Table 4).

$$
\text { Habitat, Roads, and Time of Day }
$$

Of the 99 photo-captures, 49 were taken in canyon habitat, which represented only $27 \%$ of the area surveyed. The density estimate for bobcats in canyon habitat (using trial DC4) was $0.35 \cdot \mathrm{km}^{-2}$ (95\% C.I. $\left.0.35-0.63\right)$. The percentages of bobcats photo-captured on roads (32\%) and trails (68\%) were directly proportional to the percentages of cameras set up on roads $(31 \%)$ and trails $\left(69 \% ; \chi^{2}{ }_{1}=0.0008, P=0.98\right)$. The percentage of bobcats photographed during hours of darkness was $91 \%$ (90 of 99 photos). Eight of the daylight photos were from cameras 
TABLE 3. The effect of duration of a camera session on the number of photo-captures and the population estimate. Comparisons were made among 5, 7, and 9 weeks from the DC1 trial (camera density $=1$ camera $\left.\cdot \mathrm{km}^{-2}\right)$ covering 45 $\mathrm{km}^{2}$.

\begin{tabular}{lcccccc}
\hline $\begin{array}{l}\text { No. of } \\
\text { weeks }\end{array}$ & $\begin{array}{c}\text { Individuals } \\
\text { photo-captured }\end{array}$ & $\begin{array}{c}\text { No. of } \\
\text { recaptures }\end{array}$ & $\begin{array}{c}\text { Probability of } \\
\text { capture }\end{array}$ & $\begin{array}{c}\text { Population } \\
\text { estimate }\end{array}$ & $s_{\bar{x}}$ & 95\% C.I. \\
\hline 5 & 5 & 7 & 0.480 & 5 & 0.490 & $5-6$ \\
7 & 5 & 13 & 0.486 & 5 & 0.226 & $5-6$ \\
9 & 6 & 19 & 0.444 & 6 & 0.177 & $6-6$ \\
\hline
\end{tabular}

TABLE 4. The effect of size of the area covered in photo-traps on bobcat population and density estimates (camera density $=1$ camera $\cdot \mathrm{km}^{-2}$ ). These data were taken from increasingly larger portions of the DC1 and DCP-B1 trials.

\begin{tabular}{|c|c|c|c|c|c|c|}
\hline $\begin{array}{l}\text { No. of } \\
\text { weeks }\end{array}$ & $\begin{array}{l}\text { Area trapped } \\
\qquad\left(\mathrm{km}^{2}\right)\end{array}$ & $\begin{array}{c}\text { Individuals } \\
\text { photographed }\end{array}$ & $\begin{array}{l}\text { No. of } \\
\text { weeks }\end{array}$ & $\begin{array}{l}\text { Population } \\
\text { estimate }\end{array}$ & $\begin{array}{l}95 \% \\
\text { C.I. }\end{array}$ & $\begin{array}{l}\text { Density } \\
\text { estimate }\end{array}$ \\
\hline \multicolumn{7}{|l|}{ DC1 } \\
\hline 5 & 10 & 3 & 7 & 3 & $3-5$ & $0.17-0.28$ \\
\hline 5 & 25 & 3 & 7 & 3 & $3-5$ & $0.08-0.12$ \\
\hline 5 & 45 & 5 & 7 & 5 & $5-6$ & $0.07-0.11$ \\
\hline \multicolumn{7}{|c|}{ DCP-B1 } \\
\hline 8 & 10 & 6 & 1 & 6 & $6-8$ & $0.35-0.61$ \\
\hline 8 & 15 & 7 & 2 & 7 & $7-8$ & $0.26-0.53$ \\
\hline 8 & 24 & 8 & 2 & 8 & $8-9$ & $0.28-0.41$ \\
\hline
\end{tabular}

TABLE 5. Trials conducted at Hopland (HREC) and in the Dye Creek Preserve backcountry (DCP-B).

\begin{tabular}{lccc}
\hline & HREC & DCP-B1 & DCP-B2 \\
\hline Date & Oct-Nov 1997 & Apr-Jun 1998 & Apr-Jun 1998 \\
Operational times & $18: 00-6: 00$ & $16: 30-7: 30$ & $16: 30-7: 30$ \\
Setup & Unbaited & Unbaited & Scented \\
Length of study (weeks) & 6 & 24 & 8 \\
Area trapped $\left(\mathrm{km}^{2}\right)$ & 24 & 1 & 24 \\
Camera density $\left(\right.$ cameras $\left.\cdot \mathrm{km}^{-2}\right)$ & 0.5 & 1200 & 1 \\
Trap-nights & 480 & 0.21 & 1200 \\
Capture probability & 0.41 & 8 & - \\
Population estimate & 10 & 1.47 & - \\
$s_{\bar{x}}$ & 1.44 & 28.1 & - \\
Area sampled $\left(\mathrm{km}^{2}\right)$ & 25.9 & $0.28(0.28-0.41)$ & - \\
Bobcats $\cdot \mathrm{km}^{-2}$ estimate & $0.39(0.39-0.51)$ & \\
\hline
\end{tabular}

farthest from human habitation, while 1 was from a nearby camera.

For the 2 trials conducted at DCP-B, detection efficiency was $43 \%$ (10 of 23 photos) for DCP-B1 where no attractant was used, compared with 14\% (3 of 22 photos) for DCP-B2 where an attractant was used at each camera station $\left(\chi^{2}{ }_{1}=3.99, P=0.0455\right.$; Table 5). Of the 3 photo-captures at the off-road sites in DCP$\mathrm{B} 2$, none was usable for individual identification. Although cameras in DCP-B1 and DCPB2 were operational for only 15 hours per day (16:30-07:30), $47 \%$ of bobcat photographs were taken during daylight. Significantly more daytime photographs occurred at DCP-B than during other trials at DCP $\left(\chi^{2}{ }_{1}=21.4, P<\right.$
0.001). Bobcat density at HREC was significantly higher than for either DCP $\left(\chi^{2}{ }_{1}=5.33\right.$, $P=0.021)$ or DCP-B $\left(\chi^{2}{ }_{1}=4.32, P=0.037\right.$; Table 5).

\section{DISCUSSION}

\section{Bobcat Identification}

Bobcats were readily distinguished using a single camera per station as opposed to 2 per station used in other photographic mark-recapture studies (e.g., Karanth and Nichols 1998). Sufficient variation in pelage markings allowed individuals to be identified from photographs with confidence. Photo-identification was facilitated by the high quality of the photographs. 
Only $9 \%$ of photos had to be discarded because they were out of focus or taken at a poor angle. In addition, $66 \%$ of the usable photographs showed the bobcat looking directly at the camera, allowing the use of variable facial markings, which high percentage was likely due to the short camera trigger time (pulse delay of 2), which allowed just enough time for bobcats to react to the noise of the camera and turn towards it. Particular attention was given to the placement of cameras at locations along trails and roads where bobcats were likely to travel and to the blending of camera sets into the surroundings.

Because of the many facial photos, we often were able to match photos from different sides of an animal. For example, a "right side with face" photo could be matched to a "left side with face" photo (Fig. 1). We then had photos of both flanks for matching future photos. In addition, a number of photographed bobcats had distinct scars on their ears that allowed matching of an individual from either side. Greater numbers of recaptures increased the chance that the face and both sides of an individual were recorded. As a result, the overall number of B-type comparisons decreased as number of recaptures increased. Because of the many photos that included faces, we found that we rarely needed to make B-type comparisons, and in some trials we did not make any.

\section{Factors Affecting Photo-Capture}

An important objective of this study was to determine how to best use camera stations so as to maximize photo-captures of different individuals. It has been argued that this objective is most efficiently accomplished by first identifying the few "hotspots" (e.g., scent stations) that cats in an area regularly visit and then placing camera stations at those locations (e.g., Karanth and Nichols 1998). An advantage of this approach is that relatively few cameras are needed. However, this strategy assumes that all animals in an area are likely to visit the same sites. Alternatively, cameras can be more evenly distributed in an area. For example, a grid system can be used in which cameras are placed at the best locations within fixed grid squares (e.g., along trails or roads where spoor is found).

The results from this study suggest that for bobcats, a compromise between the 2 approaches is best. Of the total camera stations (pooled for the different camera densities) only $27.8 \%$ had photo-captures. Therefore, over $70 \%$ of the cameras placed in grids did not contribute any data. On the other hand, no camera station photographed more than 2 individuals despite as many as 15 photo-captures at a single site (Fig. 4). So while a few hotspots occurred, the cameras in those spots recaptured the same 1 or 2 individuals. Increasing camera density did result in an increase in the number of camera stations with photo-captures together with an increase in the number of individuals photo-captured (Fig. 3). Bobcats were no more likely to be captured during the 2nd half of the study than they were during the 1st half, so cameras could be moved during the trial without affecting capture rates. Cameras with many photo-captures captured a bobcat in the first 2 weeks. These results support a grid-based strategy where unproductive cameras can be moved to potentially better locations (e.g., where fresh tracks or spoor are observed) within the same grid square. This preserves an even density of cameras, allowing all individuals an opportunity to be photocaptured while increasing the potential of choosing a productive location.

Extending the duration of a camera session can also increase the number of photo-captures and the number of individuals detected (Table 3). However, this effect did not appear to be as strong as the effect of increasing camera density. If the number of cameras is limited, it is possible to enhance camera efficiency by either moving unproductive cameras in a grid system, as suggested above, or by using successive sampling periods in adjacent areas that are small enough to achieve the desired camera density. The data from the different areas can then be combined by week (e.g., week 1 captures, week 2 captures, etc.), and the length of each individual survey can be used as the duration of the sampling period. In either case, it is important that sessions not be so long that they violate the assumption of demographic closure.

In this study, camera stations were placed along roads or trails, which also enhanced the likelihood of photo-captures. This was true even in the relatively open oak woodland habitat of DCP. When we attempted to use a scent lure to photo-capture bobcats away from roads and trails we obtained significantly fewer photographs. Furthermore, not 1 of the off-road photographs was usable to identify individuals. Not 
only were the bobcats photographed at poor angles, but they were also photographed investigating the scent, and as a result their facial markings were obscured. Similar negative results at scented stations have been documented with coyotes (Larrucea et al. 2007) as well as with wolves and hyenas in Syria (G. Serra unpublished data).

A final factor that affected photo-captures at DCP was human activity in an area. This was indicated by a greater proportion of diurnal photo-captures at the remote site (DCP-B), where human presence was relatively less. A possible explanation is that bobcats used roads less often in areas of higher human activity as suggested by Lovallo and Anderson (1996). However, this explanation is not supported by our off-road surveys using scent attractants. Those surveys had a detection efficiency of $13 \%$ compared with the on-road surveys, which had a detection efficiency of $43 \%$. In areas of greater human disturbance, bobcats may be more active at night, while in areas with low human disturbance, bobcats may be more active diurnally. This pattern was observed on a smaller scale at the $10-\mathrm{km}^{2}$ DCP study site, where 8 of the 9 diurnal photos were taken in the most remote parts of the study area. This result suggests that in areas with little human traffic, 24-hour camera surveillance would be efficient, while in areas with considerable human activity, nighttime surveys would be more efficient.

\section{Assumptions of Mark-Recapture Models}

Estimating animal abundance with closed capture models requires that certain assumptions be met. The short duration of the individual camera sessions likely minimized the effects of immigration and emigration such that the assumption of demographic closure was not violated. In addition, this study was conducted in an area where human interference was minimal and no trapping or hunting of bobcats was taking place. Furthermore, all individuals photographed during the low-density study phase (DC2) were photographed during the highdensity phase (DC3), indicating that the same population was present in both phases. The assumption that pelage markings did not change through the 5-8 weeks of a camera session is also reasonable. If pelage patterns remained the same throughout different shedding cycles, then this method could be used to identify individuals throughout their entire adult life. We have some evidence that this is the case. We photographed 1 bobcat with matching pelage patterns during 4 different sessions that spanned different seasons and 2 years (DC2, DC3, DC4, and DC6). Although the length of the fur changed, as well as the animal's condition, the pelage markings remained the same (Fig. 1).

The assumption that all bobcats in the area were equally likely to be photo-captured is hard to assure with confidence. Marking and recapture in this study were passive in the sense that bobcats did not have to detect and approach the camera stations. Consequently, sex, age, and social status would seem unlikely to affect which bobcats were photographed, as might happen with detection at scent posts. However, Séquin et al. (2003) found that coyote photo-captures were biased depending on social status. But bobcats seemed less wary of the camera stations than coyotes as evidenced by the relaxed posture of bobcats in photos. In contrast, coyotes were usually photographed in flight (Séquin et al. 2003). In addition, the same bobcats were photographed at the same stations on multiple occasions, indicating that they were not avoiding camera stations. Bobcats occasionally marked cameras by spraying them and still continued to be photographed at these sites. Only 1 kitten was photo-captured at a scented station (DCP-B2). It is most likely that kittens passed below the infrared beam or followed behind adults within the 2-minute camera delay. If behavioral effects were present, they likely affected all the trials in a similar fashion.

Habitat and Bobcat Density

Data obtained from the 3 study sites allowed comparisons of bobcat density estimates between geographically and ecologically different areas. The difference between the estimated density values for DCP $(0.27$ bobcats . $\left.\mathrm{km}^{-2}\right)$ and HREC $\left(0.39\right.$ bobcats $\left.\cdot \mathrm{km}^{-2}\right)$ is consistent with reports of typically smaller average bobcat home ranges (i.e. higher density) in western coastal regions than in more open and arid areas of the western interior (McCord and Cardoza 1982, Witmer and deCalesta 1986). These differences are likely due to the more uniform distribution of seasonal drainages with steep, rocky banks and dense vegetative cover at HREC (Bailey 1974, Litvaitis et al. 1986, 
Koehler 1987). In addition, coyote territories at HREC were found to be smaller in size than those at DCP (Neale 1996), indicating a higher prey base. At DCP we found bobcat density in canyon habitat $\left(0.35\right.$ bobcats $\left.\cdot \mathrm{km}^{-2}\right)$ to be similar to that at HREC, supporting a preference in bobcats for steep and vegetated terrain.

\section{ACKNOWLEDGMENTS}

We thank the staff of the Hopland Research and Extension Center and the Dye Creek Preserve for their cooperation. This work was supported by the California Agricultural Experiment Station (Project 6115MS) and by the USDA APHIS WS National Wildlife Research Center through cooperative agreement 987405-0235 (CA) with the University of California at Berkeley. The Pinelli Foundation (Florence, Italy) financially supported G. Serra.

\section{Literature Cited}

Anderson, E.M. 1987. A critical review and annotated bibliography of literature on the bobcat. Colorado Division of Wildlife, Terrestrial Wildlife Research Special Report No. 62.

BAILEY, T.N. 1974. Social organization in a bobcat population. Journal of Wildlife Management 38:435-446.

Conner M.C., R.F. Labisky, and D.R. Progulske. 1983. Scent-station indices as measures of population abundance for bobcats, raccoons, gray foxes and opossums. Wildlife Society Bulletin 11:146-152.

Diefenbach, D.R., M.J. Conroy, R.J. Warren, W.E. James, L.A. BAKER, AND T. Hon. 1994. A test of the scentstation survey technique for bobcats. Journal of Wildlife Management 58:10-17.

GoLDEN, H.N. 1995. Wildlife research and management: furbearer track county index testing and development. Alaska Department of Fish and Game, Project Number AK W-024-1/ Study 7.17. 52 pp.

Heilbrun, R.D., N.J. Silvy, M.E. Tewes, and M.J. PeterSON. 2003. Using automatically triggered cameras to individually identify bobcats. Wildlife Society Bulletin 31:748-755.

Hibi, A.R., AND J.S. JefFerr. 1987. Census techniques for small populations, with special reference to the Mediterranean monk seal. Symposium of the Zoological Society of London 58:193-210.

Jacobson, H.A., J.C. Kroll, R.W. Browning, B.H. KoERTH, AND M.H. Conway. 1997. Infrared-triggered cameras for censusing white-tailed deer. Wildlife Society Bulletin 25:547-556.

Jenkins, J.H., E.E. Provost, T.T. Fendley, J.R. Monroe, I.L. Brisbin, JR., and M.S. Lenarz. 1979. Techniques and problems with a consecutive twenty-five year furbearer trapline census. Bobcat Research Conference Proceedings, National Wildlife Federation, Science and Technology Series 6:92-96.

Johnson, K.G., AND M.R. Pelton. 1981. A survey of procedures to determine relative abundance of furbearers in the southeastern United States. Proceedings of the Annual Conference of the Southeastern Association of Fish and Wildlife Agencies 35:261- 272

Karanth, K.U. 1995. Estimating tiger Panthera tigris populations from camera-trap data using capturerecapture models. Biological Conservation 71:333338.

Karanth, K.U., AND J.D. NiChOLS. 1998. Estimation of tiger densities in India using photographic captures and recaptures. Ecology 79:2852-2862.

KaWANishi, K., AND M.E. Sunquist. 2004. Conservation status of tigers in a primary rainforest of peninsular Malaysia. Biological Conservation 120:329-344.

Koenler, G. 1987. The bobcat. Audubon Wildlife Report 1987. Academic Press, New York.

Kucera, T.E., And R.H. Barrett. 1993. The Trailmaster camera system for detecting wildlife. Wildlife Society Bulletin 21:505-508.

Larrucea, E.S., P.F. Brussard, M.M. Jaeger, and R.H. Barrett. 2007. Cameras, coyotes, and the assumption of equal detectability. Journal of Wildlife Management 71:1682-1689.

LinhaRT, S.B., AND F.F. KNOWLTON. 1975. Determining the relative abundance of coyotes by scent station lines. Wildlife Society Bulletin 3:119-124.

Litvaitis, J.A., J.A. Sherburne, and J.A. Bissonette. 1986. Bobcat habitat use and home range size in relation to prey density. Journal of Wildlife Management 50:110-117.

Lovallo, M.J., AND E.M. ANDERson. 1996. Bobcat movements and home ranges relative to roads in Wisconsin. Wildlife Society Bulletin 24:71-76.

Mace, R.D., S.C. Minta, T.L. Manley, and K.E. Aune. 1994. Estimating grizzly bear population size using camera sightings. Wildlife Society Bulletin 22:74-83.

McCord, C.M., AND J.E. CARDOZA. 1982. Bobcat and lynx. Pages 728-766 in J.A. Chapman and G.A. Feldhamer, editors, Wild mammals of North America: biology, management and economics. Johns Hopkins University Press, Baltimore, MD.

Murphy, A.H., AND H.F. HEady. 1983. Vascular plants of the Hopland Field Station, Mendocino County, California. Wasmann Journal of Biology 41:53-96.

Neale, J.C.C. 1996. Comparative resource use by sympatric bobcats and coyotes: food habits, habitat use, activity, and spatial relationships. Master's thesis, University of California, Berkeley.

NEALE, J.C.C., AND B.N. SACKS. 2001. Resource utilization and interspecific relations of sympatric bobcats and coyotes. Oikos 94:236-249.

O’Brian, M., AND M. Boudreau. 1998. Species abundance as recorded by fur harvests. Northern States Trapping Newsletter 34:10-11.

SÉquin, E.S., M.M. Jaeger, P.F. Brussard, and R.H. BARRETT. 2003. Wariness of coyotes to camera traps relative to social status and territory boundaries. Canadian Journal of Zoology 81:2015-2025.

Silver, S., C. Ostro, E.T. Linde, and L.K. Marsh. 2004. The use of camera traps for estimating jaguar (Panthera onca) abundance and density using capture/ recapture analysis. Oryx 38:148-154.

Soisalo, M.K., AND S.M.C. Cavalanti. 2006. Estimating the density of a jaguar population in the Brazilian Pantanal using camera-traps and capture-recapture sampling in combination with GPS radio-telemetry. Biological Conservation 129:487-496.

Wallace, R.B., H. Gomez, G. Ayala, and F. Espinoza. 2003. Camera trapping for jaguar (Panthera onca) in 
the Tuichi Valley, Bolivia. Mastozoologia Neotropical 10:133-139.

White, G.C., D.R. Anderson, K.P. Burnham, and D.L. OTIS. 1982. Capture-recapture and removal methods for sampling closed populations. Los Alamos National Laboratory, Los Alamos, NM.

Wilson, K.R., AND D.R. ANDERson. 1985. Evaluation of density estimators of small mammal population size. Journal of Mammalogy 66:13-21.

Witmer, G.W., and D.S. DeCalesta. 1986. Resource use by unexploited sympatric bobcats and coyotes in
Oregon, USA. Canadian Journal of Zoology 64: 2333-2338.

WoOD, J.E., AND E.P. ODum. 1964. A nine-year history of furbearer populations on the AEC Savannah River Plant Area. Journal of Mammalogy 45:540-551.

Received 22 May 2006 Accepted 2 May 2007 